\title{
Reductive dechlorination of polychlorinated biphenyls is coupled to nitrogen fixation by a legume-rhizobium symbiosis
}

\author{
Chen $\mathrm{TU}^{1}$, Yongming $\mathrm{LUO}^{1,2^{*}}$, Ying $\mathrm{TENG}^{2} \&$ Peter CHRISTIE ${ }^{2}$ \\ ${ }^{1}$ Key Laboratory of Coastal Environmental Processes and Ecological Remediation, Yantai Institute of Coastal Zone Research, \\ Chinese Academy of Sciences, Yantai 264003, China; \\ ${ }^{2}$ Key Laboratory of Soil Environment and Pollution Remediation, Institute of Soil Science, \\ Chinese Academy of Sciences, Nanjing 210008, China
}

Received February 27, 2017; accepted November 2, 2017; published online December 27, 2017

\begin{abstract}
Chlorinated persistent organic pollutants, including polychlorinated biphenyls (PCBs), represent a particularly serious environmental problem and human health risk worldwide. Leguminous plants and their symbiotic bacteria (rhizobia) are important components of the biogeochemical cycling of nitrogen in both agricultural and natural ecosystems. However, there have been relatively few detailed studies of the remediation of PCB-contaminated soils by legume-rhizobia symbionts. Here we report for the first time evidence of the reductive dechlorination of 2,4,4'-trichlorobiphenyl (PCB 28) by an alfalfa-rhizobium nitrogen fixing symbiont. Alfalfa (Medicago sativa L.) inoculated with wild-type Sinorhizobium meliloti had significantly larger biomass and PCB 28 accumulation than alfalfa inoculated with the nitrogenase negative mutant rhizobium SmY. Dechlorination products of PCB 28, 2,4'-dichlorobiphenyl (PCB 8), and the emission of chloride ion $\left(\mathrm{Cl}^{-}\right)$were also found to decrease significantly in the ineffective nodules infected by the mutant strain SmY. We therefore hypothesize that $\mathrm{N}_{2}$-fixation by the legume-rhizobium symbiont is coupled with the reductive dechlorination of PCBs within the nodules. The combination of these two processes is of great importance to the biogeochemical cycling and bioremediation of organochlorine pollutants in terrestrial ecosystems.
\end{abstract}

Keywords Biogeochemical cycling, Legume-rhizobia symbiosis, Microbe-assisted phytoremediation, Nitrogen fixation, Polychlorinated biphenyls, Soil pollution and remediation, Reductive dechlorination

Citation: Tu C, Luo Y M, Teng Y, Christie P. 2018. Reductive dechlorination of polychlorinated biphenyls is coupled to nitrogen fixation by a legumerhizobium symbiosis. Science China Earth Sciences, 61: 285-291, https://doi.org/10.1007/s11430-017-9131-9

\section{Introduction}

Polychlorinated biphenyls (PCBs) are a class of typical persistent organic pollutants (POPs) of global concern. The extensive use of PCBs coupled with improper disposal practices has resulted in widespread environmental contamination of soils, sediments, water and air (Wiegel and Wu, 2000; Dercová et al., 2008). Once in the environment, PCBs tend to bioaccumulate through the food chain due to their lipophilicity, subsequently causing adverse effects on

\footnotetext{
* Corresponding author (email: ymluo@yic.ac.cn)

ecosystems and human health (Borja et al., 2005). Phytoremediation is a promising technology to clean up contaminated soils which has entered the phase of active development during the last decade (Schnoor et al., 1995; Macek et al., 2000; Passatore et al., 2014; Thijs et al., 2016). Plants are able to take up PCBs from contaminated soils and transform them to non-phytotoxic compounds (Van Aken et al., 2010; Kurzawova et al., 2012). However, due to their high hydrophobicity, phytoremediation of PCBs is often incomplete and inefficient (Weyens et al., 2009). Microbeassisted phytoremediation has recently emerged as an effective and inexpensive strategy to detoxify or destroy PCB 
contaminants through plant-microbe interactions (Barac et al., 2004; Marx, 2004; Leigh et al., 2006; Becerra-Castro et al., 2013). This has become a key factor in the achievement of green and sustainable remediation of POP-contaminated soils (Kurzawova et al., 2012; Thijs et al., 2016).

The legume-rhizobia symbiosis is possibly the best-known natural combination that has a beneficial soil enrichment effect, contributing about $80 \%$ of the global biological $\mathrm{N}_{2}$ fixation in agriculture (Ramos and Bisseling, 2004). Rhizobia are found ubiquitously in contaminated environments where various toxic chemicals are present. Several species in the genus Rhizobium are able to utilize PCBs, polycyclic aromatic hydrocarbons (PAHs), or heterocyclic aromatic compounds as carbon substrates (Hussien et al., 1974; Ahmad et al., 1997; Chen et al., 2005; Keum et al., 2006; Poonthrigpun et al., 2006; Tu et al., 2011; Wang et al., 2016). Alfalfa (Medicago sativa L.) is a host plant of rhizobia and has been demonstrated to have a high potential for the remediation of a number of organic contaminants including PCBs (Chekol and Vough, 2001; Mehmannavaz et al., 2002). Our previous study found that the removal of PCBs from soil was enhanced by planting with alfalfa, and removal from the rhizosphere was further enhanced by inoculating the alfalfa with rhizobia. The inoculum stimulated plant growth and modified the rhizosphere soil microbial populations to facilitate PCB degradation (Teng et al., 2010, 2015; Xu et al., 2010; Luo, 2016). Furthermore, we have found significantly higher concentrations of PCBs in symbiotic nodules than in the roots or shoots (Sun et al., 2011). However, little is known about the fate of PCBs within the symbiotic $\mathrm{N}_{2}$-fixing nodules, and the mechanisms driving specific alfalfa-rhizobium interactions that result in successful biotransformation of PCBs remain incompletely understood. Here, we report for the first time the reductive dechlorination of PCBs in symbiotic nodules of Medicago sativa inoculated with $\mathrm{Si}$ norhizobium meliloti wild-type strain 1021 and nif A mutant strain SmY, and we suggest that the $\mathrm{N}_{2}$-fixation of the model association is strongly coupled with the reductive dechlorination of PCBs. We believe that the combination of these two processes may be of great importance to the biogeochemical cycling and bioremediation of organo-chlorine pollutants in terrestrial ecosystems.

\section{Materials and methods}

\subsection{Bacteria and chemical reagents}

The wild-type rhizobial strain Sinorhizobium meliloti 1021 and its nifA gene mutant strain SmY used in the present study were kindly donated by Professor Yu G Q, Institute of Plant Physiology and Ecology, Shanghai Institutes for Biological Sciences, Chinese Academy of Sciences. The mutation of nifA gene was performed by Yang et al. (2004). Briefly, a 1.5 kb DNA fragment containing the kanamycin-resistant gene $\left(K \mathrm{~m}^{\mathrm{r}}\right)$ was inserted into the nifA gene of the wild-type strain Sm1021 chromosome to mediate the insertional inactivation. The two strains were inoculated separately onto yeast mannitol (YM) agar plates at $28^{\circ} \mathrm{C}$ for $48 \mathrm{~h}$ and then sub-cultured in $100 \mathrm{~mL}$ of sterile $\mathrm{YM}$ medium at $28^{\circ} \mathrm{C}$ on a rotary shaker at $200 \mathrm{rpm}$ for two days. Standard samples of PCB 8 and PCB 28 were purchased from AccuStandard (New Haven, $\mathrm{CT})$.

\subsection{Pot experiment}

Before sowing, seeds of alfalfa (Medicago sativa L.) were surface sterilized in a $10 \%(v / v)$ solution of hydrogen peroxide for $10 \mathrm{~min}$ and rinsed six times with sterile distilled water. After germination on moist sterile filter paper at $28^{\circ} \mathrm{C}$ for $24 \mathrm{~h}$, seedlings were inoculated with a bacterial culture of wild-type (AW) or mutant strain SmY (AS) of S. meliloti. Uninoculated alfalfa seedlings were also prepared as a control (A). The seedlings were then transferred into doublelayer glass pots (Figure 1) with all treatments in triplicate. Sterilized vermiculite/perlite mixture $(m / m, 1: 1)$ was transferred to form the top layer with nitrogen-free nutrient solution below. The pots were incubated in a greenhouse with a 14-h photoperiod at $25^{\circ} \mathrm{C}$ and a 10 -h dark period at $20^{\circ} \mathrm{C}$. After plant growth for 45 days, PCB 28 dissolved in acetone was added to the nitrogen-free nutrient solution in each pot to a final concentration of $2 \mathrm{mg} \mathrm{L}^{-1}$. Plants were harvested about three weeks after PCB 28 addition.

\subsection{Analysis of PCBs in plant samples}

Plants recovered from the pots were washed with running tap water, rinsed with distilled water and separated into roots, shoots, and nodules. Samples were then freeze dried and their dry weight was recorded. The extraction and cleanup of PCB from plant samples were performed according to Gao et al. (2006) with some modifications. Approximately $2 \mathrm{~g}$ of dry plant sample was extracted with $30 \mathrm{~mL}$ hexane/acetone $(1: 1 \mathrm{v} / \mathrm{v})$ overnight and sonicated at $600 \mathrm{~W}, 25^{\circ} \mathrm{C}$ for $15 \mathrm{~min}$ with a Model KQ-600B sonicator (Kunshan Ultrasonic Instruments, China). Extraction and ultrasonication were repeated twice using $20 \mathrm{~mL}$ of the same solvent mixture each time. The extracts were combined and collected in $120 \mathrm{~mL}$ glass vials. Extract volumes were concentrated to $5 \mathrm{~mL}$ using a rotary evaporator. Each extract was then transferred to a $25 \mathrm{~cm} \times 1 \mathrm{~cm}$ purification column containing silica gel, $\mathrm{Al}_{2} \mathrm{O}_{3}$, acidic silica gel and $\mathrm{Na}_{2} \mathrm{SO}_{4}$ powder in sequence. The column was eluted with $25 \mathrm{~mL}$ of $n$-hexane, the eluate was concentrated until nearly dry $(<1 \mathrm{~mL})$, then dissolved in $\mathrm{n}$ hexane to a final volume of $5 \mathrm{~mL}$, and $2 \mathrm{~mL}$ of the eluate were transferred to an auto-sampler vial for analysis.

Analysis was conducted using a Varian 3800 gas chro- 
(a)

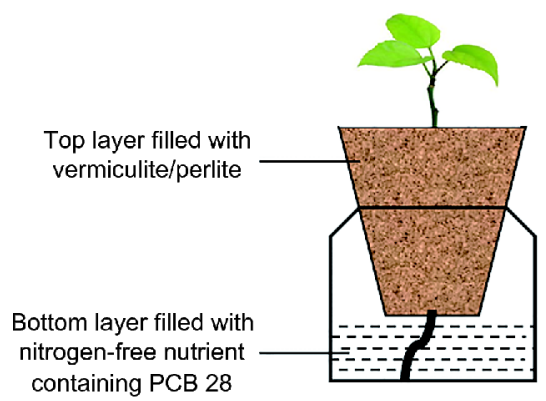

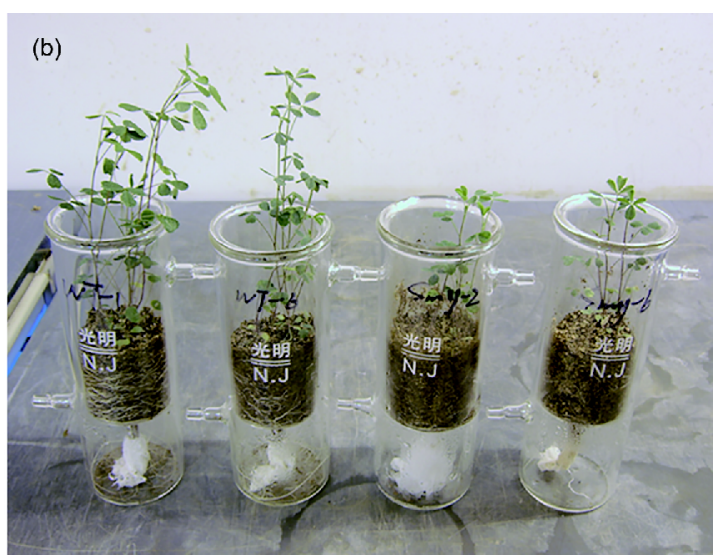

Figure 1 The double-layer glass pots used in this study. (a) Design model of the double-layer pot. (b) Actual products with nutrient and PCB injection ports.

matograph (Agilent Technologies, Santa Clara, CA) equipped with an electron capture detector (ECD) and auto injector. A Varian CP-Sil $24 \mathrm{CB}(30 \mathrm{~m} \times 0.25 \mathrm{~mm} \times 0.25 \mu \mathrm{m})$ was used with $\mathrm{N}_{2}$ as the carrier gas. One microliter of sample extract was injected. The injector and detector chamber temperatures were 260 and $300^{\circ} \mathrm{C}$, respectively. The oven temperature was initially set at $180^{\circ} \mathrm{C}$ for $0.5 \mathrm{~min}$, ramped at $30^{\circ} \mathrm{C} \mathrm{min}^{-1}$ to $260^{\circ} \mathrm{C}$, held for $18 \mathrm{~min}$ then at $15^{\circ} \mathrm{C} \mathrm{min}^{-1}$ to $270^{\circ} \mathrm{C}$ and held for $2 \mathrm{~min}$. PCB congeners were identified by retention time matching to standards and were quantified using peak area integration.

\subsection{Measurement of nodule $\mathrm{Cl}^{-}, \mathrm{NH}_{4}^{+}$, and $\mathrm{H}^{+}$flux with the SIET system}

Net fluxes of $\mathrm{Cl}^{-}, \mathrm{NH}_{4}{ }^{+}$, and $\mathrm{H}^{+}$from the nodules were measured non-invasively using SIET (the scanning ion-selective electrode technique, SIET system BIO-003A; Younger USA Science and Technology Corp.; Applicable Electronics Inc.; Science Wares Inc., Falmouth, MA) at Xuyue Science and Technology Co., Ltd (Beijing, China). The instrumentation and the principle of the method have been described in detail previously (Xu et al., 2006; Reid et al., 2007; Sun et al., 2009). Plants were cultured as described above. After exposure to PCB 28 for 3 weeks, alfalfa with wild-type or mutant nodules was sampled for ion flux measurements performed at room temperature. Nodules were rinsed with re-distilled water and immediately incubated in the measuring solution to equilibrate for $30 \mathrm{~min}$. The equilibrated plants were then transferred to a measuring chamber containing $10 \mathrm{~mL}$ of fresh measuring solution. The central zone of the nodule was selected as the measurement site in which nitrogen fixation occurs. The background was recorded by vibrating the electrode in the measuring solution in the absence of alfalfa nodules.

$\mathrm{Cl}^{-}, \mathrm{NH}_{4}^{+}$, and $\mathrm{H}^{+}$were determined in the following solutions: (1) $\mathrm{Cl}^{-}$: $0.05 \mathrm{mmol} \mathrm{L}^{-1} \mathrm{KCl}, 0.05 \mathrm{mmol} \mathrm{L}^{-1} \mathrm{CaCl}_{2}$,
$0.05 \mathrm{mmol} \mathrm{L}^{-1} \mathrm{MgCl}_{2}, 0.25 \mathrm{mmol} \mathrm{L}^{-1} \mathrm{NaCl}, 0.3 \mathrm{mmol} \mathrm{L}^{-1}$ MES, $0.2 \mathrm{mmol} \mathrm{L}^{-1} \mathrm{Na}_{2} \mathrm{SO}_{4}, 0.1 \%$ sucrose, $\mathrm{pH} 6.0$; (2) $\mathrm{NH}_{4}^{+}$: $0.1 \mathrm{mmol} \mathrm{L}^{-1} \mathrm{NH}_{4} \mathrm{NO}_{3}, 0.1 \mathrm{mmol} \mathrm{L}^{-1} \mathrm{KCl}, 0.2 \mathrm{mmol} \mathrm{L}^{-1}$ $\mathrm{CaSO}_{4}, 0.1 \%$ sucrose, $\mathrm{pH} 6.0$; (3) $\mathrm{H}^{+}: 0.1 \mathrm{mmol} \mathrm{L}^{-1} \mathrm{KCl}$, $0.1 \mathrm{mmol} \mathrm{L}^{-1} \quad \mathrm{CaCl}_{2}, \quad 0.1 \mathrm{mmol} \mathrm{L}^{-1} \quad \mathrm{MgCl}_{2}, \quad 0.5 \mathrm{mmol} \mathrm{L}^{-1}$ $\mathrm{NaCl}, 0.3 \mathrm{mmol} \mathrm{L}{ }^{-1}$ MES, $0.2 \mathrm{mmol} \mathrm{L}{ }^{-1} \mathrm{Na}_{2} \mathrm{SO}_{4}, 0.1 \%$ sucrose, $\mathrm{pH}$ 6.0.

Silanized glass microelectrodes (XYPG120-2; Xuyue Science and Technology Co., Ltd.) were first filled with a backfilling solution $\left(\mathrm{Cl}^{-}\right.$: $100 \mathrm{mmol} \mathrm{L}^{-1} \mathrm{KCl} ; \mathrm{NH}_{4}^{+}$: $100 \mathrm{mmol} \mathrm{L}^{-1} \quad \mathrm{NH}_{4} \mathrm{Cl} ; \quad \mathrm{H}^{+}: \quad 40 \mathrm{mmol} \mathrm{L}^{-1} \quad \mathrm{KH}_{2} \mathrm{PO}_{4}$ and $15 \mathrm{mmol} \mathrm{L}^{-1} \mathrm{NaCl}$ ) to a length of approximately $1 \mathrm{~cm}$ from the tip. Then the micropipettes were front-filled with approximately $15 \mathrm{~mm}$ columns of selective liquid ion-exchange cocktails $\left(\mathrm{Cl}^{-}\right.$: Fluka 24902; $\mathrm{NH}_{4}^{+}$: Fluka 09879; $\mathrm{H}^{+}$: Fluka 95293). Ion-selective electrodes of all the target ions were calibrated before flux measurements: (1) $\mathrm{Cl}^{-}: 0.05$ and $3 \mathrm{mmol} \mathrm{L}^{-1} \mathrm{NaCl}$; (2) $\mathrm{NH}_{4}^{+}$: 0.01 and $1 \mathrm{mmol} \mathrm{L}^{-1} \mathrm{NH}_{4} \mathrm{NO}_{3}$; (3) $\mathrm{H}^{+}$: pH 6.0 and 7.0. The net fluxes of $\mathrm{Cl}^{-}, \mathrm{NH}_{4}{ }^{+}$, and $\mathrm{H}^{+}$at the wild-type nodules and mutant $\mathrm{SmY}$ nodules were measured individually. Each nodule was determined three times at different zones in the center. The final flux values at each nodule were the mean values of more than two individual plants from each treatment. Ion flux was calculated by Fick's law of diffusion:

$$
J=-D(d c / d x),
$$

where $J$ represents the ion flux in the $x$ direction, $d c / d x$ is the ion concentration gradient, and $D$ is the ion diffusion constant in a particular medium. Three-dimensional ionic fluxes were calculated using MageFlux developed by Xuyue Science and Technology Co., Ltd (http://xuyue.net/mageflux).

\subsection{Statistical analysis}

All statistical analysis was performed with the SPSS for Windows version 14.0 software package. The data were subjected to one-way analysis of variance and mean values 
were compared using Duncan's multiple range test at the 5\% level. A minimum of three data points were used for each analysis.

\section{Results and discussion}

\subsection{Plant biomass and PCB accumulation in alfalfa- rhizobium symbiosis}

The well-known model rhizobium Sinorhizobium meliloti 1021 (wild-type and strain SmY, which had undergone a mutation in the $\mathrm{N}_{2}$-fixation regulation gene nifA) was used as an inoculant of alfalfa (Medicago sativa) host plants. Concentrations of PCB 28, plant biomass, and the nitrogenase activity were determined and compared among the different plant-microbe combinations (Table 1).

The biomass of alfalfa shoots, nodules and roots inoculated with wild-type S. meliloti (AW) increased 1-, 2- and 12 times compared with alfalfa inoculated with the $\mathrm{N}_{2}$ fixing mutant strain (AS). The concentrations of PCB 28 in AW shoots and roots were 1.6- and 2.6 times higher than in AS plants, and were 1.6- and 2.9 times higher than that in uninoculated plants, indicating the enhanced phytoextraction of PCBs by rhizobium inoculation. This may be related to the stronger ability of the wild-type symbiont to alleviate nutrient limitations by $\mathrm{N}_{2}$ fixation and thereby increase shoot and root biomass, as well as to enhanced phytoextraction of PCB 28. Almost all root nodules formed on inoculation with wildtype $S$. meliloti were effective in $\mathrm{N}_{2}$-fixation as revealed by determination of nitrogenase activity, but nodules on alfalfa inoculated with the nifA mutant strain showed limited $\mathrm{N}_{2}$ fixation capacity with no nitrogenase activity detected. Furthermore, PCB 28 accumulated preferentially in lipidrich nodules rather than in the roots or shoots, possibly due to the strong lipotropy of PCBs. Variation in lipid types and distributions show positive correlations with the accumulation of organic pollutants within different plant species and tissues (Barbour et al., 2005; Sun et al., 2011; Luo, 2016).

\subsection{Reductive dechlorination of PCB 28 in the $\mathbf{N}_{2}$-fixing nodules}

The general metabolic pathway of PCBs in plants involves the enzyme cytochrome P-450 (CYP) which mediates the oxidation of PCBs to form hydroxylated metabolites and epoxides, and further to methylsulfonyl metabolites catalyzed by glutathione S-transterase (GST) (Liu et al., 2009). There are few reports on the dechlorination of PCBs in plants (Chen et al., 2005; Meggo et al., 2013). Magee et al. (2008) reported the dechlorination of PCB 153 by a crude extract of nitrate reductase from leaves of Medicago sativa. In the present study, dechlorination of PCB 28 by the alfalfa-rhizobium symbiosis was evident from visual inspection of the chromatograms of PCBs extracted after three weeks of incubation. An earlier eluting peak, corresponding to the lesser chlorinated congener 2,4'-dichlorobiphenyl (PCB 8, the likely dechlorination product of PCB 28), appeared in all nodules, roots and shoots from both wild-type and mutant rhizobium inoculated alfalfa. However, the concentrations of PCB 8 in nodules were significantly higher than in roots or shoots (Figure 2). This may also due to distinct differences in lipid content among different plant tissues. Moreover, inoculation with the wild-type (AW) S. meliloti resulted in a significantly higher concentration of PCB 8 in all tissues as compared to inoculation with the $\mathrm{N}_{2}$-fixing mutant (AS) strain. Nodules were the sites where $\mathrm{N}_{2}$-fixation took place and also the sites where dechlorination of PCBs was strongly operational. The interesting phenomenom noted above indicates a potential relationship between the two reduction processes (Luo, 2016).

\section{3 $\mathrm{Cl}^{-}, \mathrm{NH}_{4}^{+}$, and $\mathrm{H}^{+}$Fluxes in $\mathrm{N}_{2}$-fixing nodules}

To further confirm whether or not the dechlorination of $\mathrm{PCB}$ 28 was occurring within the symbiotic nodules and to determine whether or not the dechlorination intensity was correlated with the $\mathrm{N}_{2}$-fixation activity, we used a non-invasive ion flux technique to measure the ion fluxes of $\mathrm{Cl}^{-}$,

Table 1 Plant biomass, PCB concentrations and nitrogenase activities in different treatments ${ }^{\text {a) }}$

\begin{tabular}{|c|c|c|c|c|c|}
\hline Treatment & & $\begin{array}{l}\text { Plant biomass } \\
\left(\mathrm{mg} \mathrm{plant}{ }^{-1}\right)\end{array}$ & $\begin{array}{c}\text { PCB } 28 \text { concentration } \\
\left(\mu \mathrm{g} \mathrm{kg}^{-1}\right)\end{array}$ & $\begin{array}{c}\text { PCB } 28 \text { accumulation } \\
\left.(\mu \mathrm{g} \mathrm{plant})^{-1}\right)\end{array}$ & $\begin{array}{c}\text { Nitrogenase activity } \\
\left(\mathrm{nmol} \mathrm{L}^{-1} \mathrm{C}_{2} \mathrm{H}_{4} \text { plant }^{-1} \mathrm{~min}^{-1}\right)\end{array}$ \\
\hline \multirow{2}{*}{ Alfalfa (A) } & Roots & $340 \pm 60$ & $366 \pm 10$ & \multirow{2}{*}{$0.14 \pm 0.001$} & \multirow{2}{*}{ ND } \\
\hline & Shoots & $890 \pm 80$ & $20 \pm 1$ & & \\
\hline \multirow{3}{*}{ Alfalfa + Wild-type (AW) } & Nodules & $380 \pm 10$ & $1150 \pm 100$ & \multirow{3}{*}{$2.03 \pm 0.003$} & \multirow{3}{*}{4.3} \\
\hline & Roots & $1430 \pm 130$ & $1072 \pm 15$ & & \\
\hline & Shoots & $1900 \pm 60$ & $32 \pm 4$ & & \\
\hline \multirow{3}{*}{ Alfalfa + SmY (AS) } & Nodules & $120 \pm 10$ & $840 \pm 111$ & \multirow{3}{*}{$0.17 \pm 0.001$} & \multirow{3}{*}{ ND } \\
\hline & Roots & $120 \pm 20$ & $406 \pm 2$ & & \\
\hline & Shoots & $1000 \pm 50$ & $20 \pm 3$ & & \\
\hline
\end{tabular}

a) Values are the means of three replicates \pm the standard error of the mean. ND: not detected. 


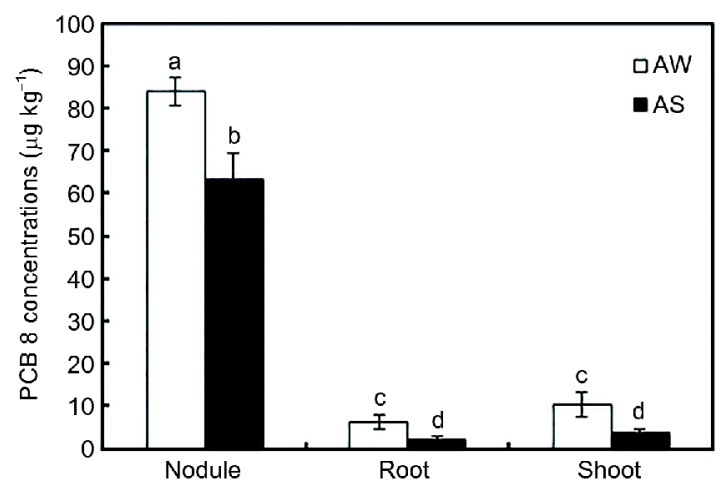

Figure 2 Concentrations of PCB 8 in different tissues of the symbionts. AW, alfalfa inoculated with wild-type S. meliloti; AS, alfalfa inoculated with mutant SmY S. meliloti. Error bars, standard errors of means of triplicates. Different letters indicate a significant difference in the same column $(p<0.05)$.

$\mathrm{NH}_{4}^{+}$, and $\mathrm{H}^{+}$in root nodules of alfalfa inoculated with wildtype $S$. meliloti (AW) and the nifA mutation strain (AS), respectively. Scanning ion-selective electrode technique (SIET) data show that PCB 28 induced a net $\mathrm{Cl}^{-}$efflux (

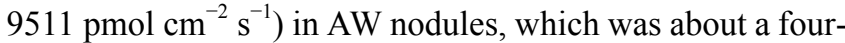
times increase above the $2535 \mathrm{pmol} \mathrm{cm}^{-2} \mathrm{~s}^{-1}$ in AS nodules (Figure 3a).

Furthermore, there were marked differences in $\mathrm{NH}_{4}^{+}$fluxes between the AW and AS symbiont nodules (Figure $3 \mathrm{~b}$ ). The enhanced efflux of $\mathrm{NH}_{4}^{+}$in the AW treatment suggests a much stronger $\mathrm{N}_{2}$-fixation activity in the wild-type nodules than the mutation treatment, whilst the enhanced efflux of $\mathrm{Cl}^{-}$in wild-type nodules indicates a more intense PCB dechlorination process. All these findings strongly suggest that the intensity of PCB 28 reductive dechlorination has a significant and positive relationship with the $\mathrm{N}_{2}$-fixation activity of the alfalfa-rhizobium association. Our particular interest was directed to the potential mechanisms under the interaction of the two distinct pathways involved (Luo, 2016).

It is widely understood that the $\mathrm{N}_{2}$-fixation process of legume-rhizobia symbionts occurs in the central zone of the root nodules. The nitrogenase enzyme complex produced by the differentiated rhizobium (bacteroids) catalyzes the following reaction:

$$
\begin{aligned}
& \mathrm{N}_{2}+16 \mathrm{ATP}+10 \mathrm{H}^{+}+8 \mathrm{e}^{-} \rightarrow \\
& 2 \mathrm{NH}_{4}{ }^{+}+\mathrm{H}_{2}+16 \mathrm{ADP}+16 \mathrm{Pi}
\end{aligned}
$$

This reaction is energetically costly and it therefore exerts a high demand for $\mathrm{O}_{2}$ to produce ATP by oxidative phosphorylation. However, high $\mathrm{O}_{2}$ concentrations irreversibly inactivate the nitrogenase complex within one minute. To overcome this dilemma, nodules have developed multiple mechanisms to maintain a low oxygen concentration in the central zone (Ramos and Bisseling, 2004). This low oxygen concentration provides a reductive environment in the central zone of the nodule $\left(10-50 \mathrm{nmol} \mathrm{L}^{-1}\right)$, which is about $10^{-4}$ of that at the nodule surface $\left(250 \mathrm{mmol} \mathrm{L}^{-1}\right)$ (Kuzma et al., 1993). The $\mathrm{H}_{2}$ is an obligate by-product of nitrogenase activity. Recycling of $\mathrm{H}_{2}$ through the uptake of hydrogenase (Hup) inside the root nodules of leguminous plants is often considered an advantage for plants. However, many of the rhizobia-legume symbionts (Sinorhizobium-Medicago included) found in nature have been shown to be Hup ${ }^{-}$, with the plants releasing $\mathrm{H}_{2}$ produced by nitrogenase from root nodules into the surrounding rhizosphere. Coincidentally, reductive dechlorination of PCBs usually takes place in an anaerobic environment with reduced organic substrate or $\mathrm{H}_{2}$ as the source of both the reducing power and the electron donors (reductant), and with PCBs as the electron acceptors. Moreover, dechlorination of PCBs is thought to be catalyzed by reductive dehalogenase (RDase) in Dehalococcoides mccartyi strains (Wang et al., 2014). However, the key functional genes and potential enzymes involved in PCB dechlorination remain unclear within the $\mathrm{N}_{2}$-fixation nodules. Here we propose a pathway which is emerging from a broad perspective of previous studies. The reductive dechlorination of PCBs is coupled with the $\mathrm{N}_{2}$-fixation process by utilizing its by-product, $\mathrm{H}_{2}$, as reductant and electron donor, followed by the removal of a chlorine substituent from a PCB molecule with concurrent addition of electrons to the molecule, under the catalysis by undefined RDases. The chlorine atoms are released as chloride anions while the hydrogen molecule is oxidized to protons. The increased $\mathrm{H}^{+}$ flux in the wild-type nodules (Figure 3c) may contribute to the redox reactions. A putative coupling mechanism of PCB dechlorination and $\mathrm{N}_{2}$-fixation in the legume-rhizobia sym-
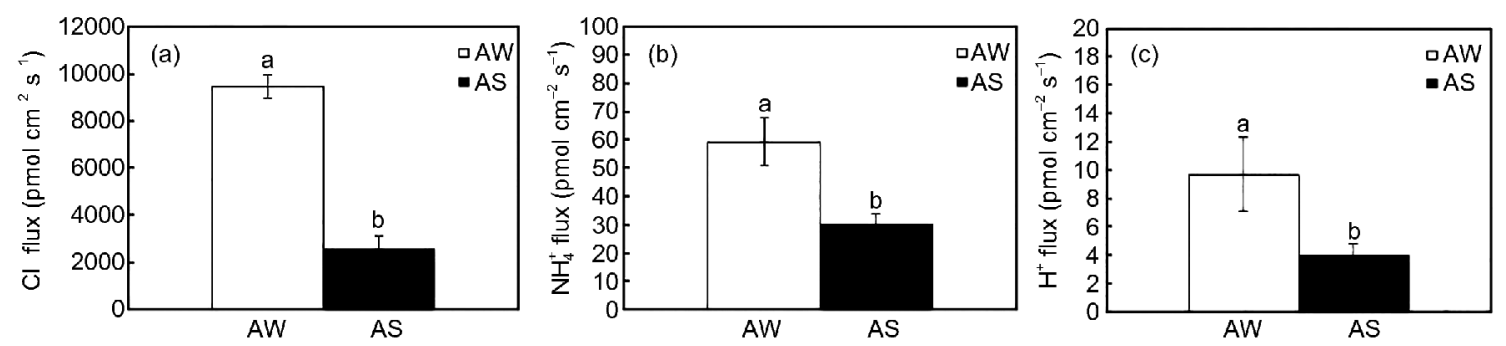

Figure $3 \mathrm{Cl}^{-}, \mathrm{NH}_{4}{ }^{+}$, and $\mathrm{H}^{+}$fluxes across the symbiont nodules. AW, alfalfa inoculated with wild-type $S$. meliloti; AS, alfalfa inoculated with mutant SmY S. meliloti. Error bars, standard errors of means of triplicates. Different letters indicate a significant difference in the same column $(p<0.05)$. 


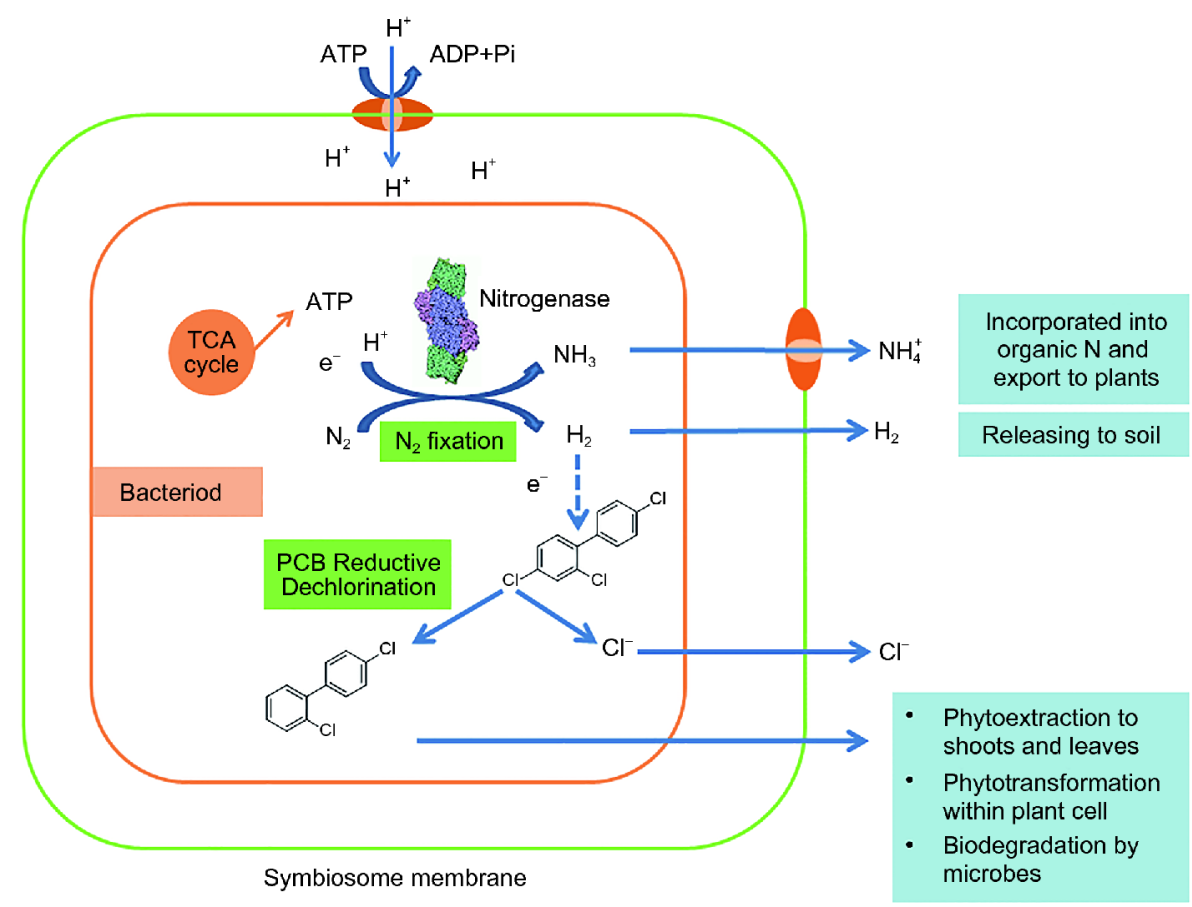

Figure 4 Putative coupling mechanism of PCB dechlorination and $\mathrm{N}_{2}$-fixing in the legume-rhizobia symbiotic nodules.

biotic nodules is presented in Figure 4.

\section{Conclusions}

Rhizobia are soil $\mathrm{N}_{2}$-fixing bacteria associated symbiotically with plant roots and the rhizosphere. The hallmark of rhizobial studies has always focused on their agricultural importance. Recent studies suggest that rhizobia, in addition to their contribution to plant growth, soil fertility and crop yield, also have positive PCB remediation effects both in vitro and in symbiotic partnership. In the current study we have found good evidence for the reductive dechlorination of PCBs in an alfalfa-Sinorhizobium association and the $\mathrm{N}_{2}$ fixation function of the symbiotic nodules was coupled with the reductive dechlorination of PCBs. These findings contribute to an improved understanding the important roles and the potential application of legume-rhizobium symbionts in the bioremediation of organochlorine-contaminated soils.

Acknowledgements The authors thank Prof. Yu $G Q$ for kindly providing $S$. meliloti wild-type and $\operatorname{Sm} Y$ mutant strains. This work was supported by the National Natural Science Foundation of China (Grant Nos. 41201313 \& 41230858).

\section{References}

Ahmad D, Mehmannavaz R, Damaj M. 1997. Isolation and characterization of symbiotic $\mathrm{N}_{2}$-fixing Rhizobium meliloti from soils contaminated with aromatic and chloroaromatic hydrocarbons: PAHs and PCBs. Int Biodeter Biodegr, 39: 33-43
Barac T, Taghavi S, Borremans B, Provoost A, Oeyen L, Colpaert J V, Vangronsveld J, van der Lelie D. 2004. Engineered endophytic bacteria improve phytoremediation of water-soluble, volatile, organic pollutants. Nat Biotechnol, 22: 583-588

Barbour J P, Smith J A, Chiou C T. 2005. Sorption of aromatic organic pollutants to grasses from water. Environ Sci Technol, 39: 8369-8373

Becerra-Castro C, Prieto-Fernández Á, Kidd P S, Weyens N, RodríguezGarrido B, Touceda-González M, Acea M J, Vangronsveld J. 2013. Improving performance of Cytisus striatus on substrates contaminated with hexachlorocyclohexane $(\mathrm{HCH})$ isomers using bacterial inoculants: Developing a phytoremediation strategy. Plant Soil, 362: 247-260

Borja J, Taleon D M, Auresenia J, Gallardo S. 2005. Polychlorinated biphenyls and their biodegradation. Process Biochem, 40: 1999-2013

Chekol T, Vough L R. 2001. A study of the use of alfalfa (Medicago sativa L.) for the phytoremediation of organic contaminants in soil. Remediation, 11: 89-101

Chen Y, Adam A, Toure O, Dutta S K. 2005. Molecular evidence of genetic modification of Sinorhizobium meliloti: Enhanced PCB bioremediation. J Ind Microbiol Biotechnol, 32: 561-566

Dercová K, Čičmanová J, Lovecká P, Demnerová K, Macková M, Hucko P, Kušnír P. 2008. Isolation and identification of PCB-degrading microorganisms from contaminated sediments. Int Biodeter Biodegr, 62: $219-225$

Gao J, Luo Y M, Li Q B, Zhang H B, Wu L H, Song J, Qian W, Christie P, Chen S M. 2006. Distribution patterns of polychlorinated biphenyls in soils collected from Zhejiang province, east China. Environ Geochem Health, 28: 79-87

Hussien Y A, Tewfik M S, Hamdi Y A. 1974. Degradation of certain aromatic compounds by rhizobia. Soil Biol Biochem, 6: 377-381

Keum Y S, Seo J S, Hu Y, Li Q X. 2006. Degradation pathways of phenanthrene by Sinorhizobium sp. C4. Appl Microbiol Biotechnol, 71: 935-941

Kurzawova V, Stursa P, Uhlik O, Norkova K, Strohalm M, Lipov J, Kochankova L, Mackova M. 2012. Plant-microorganism interactions in bioremediation of polychlorinated biphenyl-contaminated soil. New Biotech, 30: 15-22

Kuzma M M, Hunt S, Layzell D B. 1993. Role of oxygen in the limitation 
and inhibition of nitrogenase activity and respiration rate in individual soybean nodules. Plant Physiol, 101: 161-169

Leigh M B, Prouzová P, Macková M, Macek T, Nagle D P, Fletcher J S. 2006. Polychlorinated biphenyl (PCB)-degrading bacteria associated with trees in a PCB-contaminated site. Appl Environ Microbiol, 72: 2331-2342

Liu J Y, Hu D F, Jiang G B, Schnoor J L. 2009. In vivo Biotransformation of 3,3',4,4'-Tetrachlorobiphenyl by Whole Plants-Poplars and Switchgrass. Environ Sci Technol, 43: 7503-7509

Luo Y M. 2016. Remediation Mechanism and Technological Development of Toxic Organic Substance Polluted Soil (in Chinese). Beijing: Science Press. $1-80$

Macek T, Macková M, Káš J. 2000. Exploitation of plants for the removal of organics in environmental remediation. Biotech Adv, 18: 23-34

Magee K D, Michael A, Ullah H, Dutta S K. 2008. Dechlorination of PCB in the presence of plant nitrate reductase. Environ Toxicol Pharmacology, 25: 144-147

Marx J. 2004. The roots of plant-microbe collaborations. Science, 304: 234-236

Mehmannavaz R, Prasher S O, Ahmad D. 2002. Rhizospheric effects of alfalfa on biotransformation of polychlorinated biphenyls in a contaminated soil augmented with Sinorhizobium meliloti. Process Biochem, 37: 955-963

Meggo R E, Schnoor J L, Hu D. 2013. Dechlorination of PCBs in the rhizosphere of switchgrass and poplar. Environ Pollut, 178: 312-321

Passatore L, Rossetti S, Juwarkar A A, Massacci A. 2014. Phytoremediation and bioremediation of polychlorinated biphenyls (PCBs): State of knowledge and research perspectives. J Hazard Mater, 278: 189-202

Poonthrigpun S, Pattaragulwanit K, Paengthai S, Kriangkripipat T, Juntongjin K, Thaniyavarn S, Petsom A, Pinphanichakarn P. 2006. Novel intermediates of acenaphthylene degradation by Rhizobium sp. strain CU-A1: Evidence for naphthalene-1,8-dicarboxylic acid metabolism. Appl Environ Microbiol, 72: 6034-6039

Ramos J, Bisseling T. 2004. Symbiotic nitrogen fixation. In: Amâncio S, Stulen I, eds. Nitrogen Acquisition and Assimilation in Higher Pants. The Netherland: Kluwer Academic Publishers. 99-131

Reid B, Nuccitelli R, Zhao M. 2007. Non-invasive measurement of bioelectric currents with a vibrating probe. Nat Protoc, 2: 661-669

Schnoor J L, Licht L A, McCutcheon S C, Wolfe N L, Carreira L H. 1995. Phytoremediation of organic and nutrient contaminants. Environ Sci Technol, 29: 318A-323A

Sun J, Chen S, Dai S, Wang R, Li N, Shen X, Zhou X, Lu C, Zheng X, Hu Z, Zhang Z, Song J, Xu Y. 2009. NaCl-induced alternations of cellular and tissue ion fluxes in roots of salt-resistant and salt-sensitive poplar species. Plant Physiol, 149: 1141-1153

Sun X H, Teng Y, Luo Y M, Tu C, Li Z G. 2011. Accumulation, distribution and chemical speciation of PCBs in different parts of alfalfa (in Chinese). Soils, 43: 595-599

Teng Y, Wang X M, Li L N, Li Z G, Luo Y M. 2015. Rhizobia and their bio-partners as novel drivers for functional remediation in contaminated soils. Front Plant Sci, 6: 32

Teng Y, Luo Y M, Sun X H, Tu C, Xu L, Liu W X, Li Z G, Christie P. 2010. Influence of arbuscular mycorrhiza andrhizobium on phytoremediation by alfalfa of an agricultural soil contaminated with weathered PCBs: A field study. Int J Phytoremediat, 12: 516-533

Thijs S, Sillen W, Rineau F, Weyens N, Vangronsveld J. 2016. Towards an enhanced understanding of plant-microbiome interactions to improve phytoremediation: Engineering the metaorganism. Front Microbiol, 7

Tu C, Teng Y, Luo Y M, Li X H, Sun X H, Li Z G, Liu W X, Christie P. 2011. Potential for biodegradation of polychlorinated biphenyls (PCBs) by Sinorhizobium meliloti. J Hazard Mater, 186: 1438-1444

Van Aken B, Correa P A, Schnoor J L. 2010. Phytoremediation of Polychlorinated Biphenyls: New Trends and Promises ${ }^{\dagger}$. Environ Sci Technol, 44: 2767-2776

Wang S, Chng K R, Wilm A, Zhao S, Yang K L, Nagarajan N, He J. 2014. Genomic characterization of three unique Dehalococcoides that respire on persistent polychlorinated biphenyls. Proc Natl Acad Sci USA, 111: 12103-12108

Wang X M, Teng Y, Luo Y M, Dick R P. 2016. Biodegradation of 3,3',4,4'tetrachlorobiphenyl by Sinorhizobium meliloti NM. Bioresource Tech, 201: 261-268

Weyens N, van der Lelie D, Taghavi S, Newman L, Vangronsveld J. 2009. Exploiting plant-microbe partnerships to improve biomass production and remediation. Trends Biotech, 27: 591-598

Wiegel J, Wu Q. 2000. Microbial reductive dehalogenation of polychlorinated biphenyls. Fems Microbiol Ecology, 32: 1-15

Xu L, Teng Y, Li Z G, Norton J M, Luo Y M. 2010. Enhanced removal of polychlorinated biphenyls from alfalfa rhizosphere soil in a field study: The impact of a rhizobial inoculum. Sci Total Environ, 408: 1007-1013

Xu Y, Sun T, Yin L P. 2006. Application of non-invasive microsensing system to simultaneously measure both $\mathrm{H}^{+}$and $\mathrm{O}_{2}$ fluxes around the pollen tube. J Integrative Plant Biol, 48: 823-831

Yang C T, Yu G Q, Shen S J, Zhu J B. 2004. Functional difference between Sinorhizobium meliloti NifA and Enterobacter cloacae NifA. Sci China Ser C-Life Sci, 47: 44-51 